\title{
Multimodality therapy for metastatic sarcomas confined to the lung (Review)
}

\author{
RUSSELL P. GOLLARD ${ }^{1}$ and J. FRANCIS TURNER ${ }^{2}$ \\ ${ }^{1}$ Honors College; ${ }^{2}$ National Supercomputing Center for Energy and the Environment, \\ School of Medicine, University of Nevada, Las Vegas NV 89154, USA
}

Received March 27, 2012; Accepted July 10, 2012

DOI: $10.3892 / \mathrm{ol} .2012 .820$

\begin{abstract}
Metastectomy or resection of sarcomas which have metastasized to the lung from other sites has a long and established history. At present, there are more than forty different drugs with activity in soft tissue sarcomas. A number of sarcomas demonstrate differential sensitivities to chemotherapy and targeted agents. Intimate knowledge of the biological behavior of each distinct type of sarcoma should predicate what treatment or protocol is most suitable. Certain patients might benefit from either neoadjuvant or adjuvant therapy following the resection of metastatic lesions. Much remains to be learned about the differential sensitivities of various sarcomas to different treatment regimens.
\end{abstract}

\section{Contents}

1. Multimodality therapy for pulmonary soft tissue sarcomas

2. Imaging modalities

3. Surgical approaches and techniques

4. Radiation therapy

5. Chemotherapy and targeted therapy

\section{Multimodality therapy for pulmonary soft tissue sarcomas}

Sarcomas of the lung present a difficult problem. They are uncommon, and it should first be determined if they are primary or secondary to sarcomas in other parts of the body. The multiplicity of different types of sarcomas, both soft tissue and bone/cartilage, a number of which demand therapy tailored to the specific cell type and grade, make it incumbent

Correspondence to: Dr Russell P. Gollard, Cancer and Blood Specialists of Nevada, 58 N. Pecos Road, Henderson, NV 89074, USA

E-mail: rgollard@hotmail.com

Key words: lung sarcoma, multimodality treatments, soft tissue sarcoma for the treating oncologist, pulmonologist and surgeon to have an intimate knowledge of the differential treatment regimens and protocols for this group of similar yet distinct tumors. It must first be determined whether the tumors are primary to the lung or the result of metastases from elsewhere in the body. Metastectomy has a long history in the management of multiple tumors from other sites that have spread to the lungs, particularly late recurrences from primary sarcomas extirpated from other parts of the body. The natural history of metastatic sarcomas in the lung is terminal (1-3). Colorectal adenocarcinomas, which are far more common than sarcomas, commonly spread to the lungs and are often resected and chemotherapy is administered neoadjuvantly or adjuvantly. These resections may be completed for cure.

Even amongst extremely rare sarcomas encountered in the lung, resections may occasionally be completed for cure in lesions sensitive to treatment if the differential sensitivity to both cytotoxic and targeted therapy is considered and the tumors are treated with these differential sensitivities in mind. Adult sarcomas are rare both individually and collectively. With approximately 12,000 cases reported in the United States every year, even the more 'common' types of sarcomas are found in relatively small numbers (American Cancer Society website; www.cancer.org). Malignant fibrous histiocytomas, liposarcomas and leiomyosarcomas are the most common soft tissue sarcomas encountered in adults. Generally, extremity sarcomas have a better prognosis than truncal sarcomas. When a non-calcified soft tissue mass is found within the thorax, a core needle biopsy should be used to determine the histology of the lung lesion. A thorough physical examination, including a gynecological examination for females, should be completed prior to obtaining expensive imaging.

Similar to lymphomas, sarcomas are derived from the mesoderm and a number are characterized by fusion translocations (Table I) (4). Oncogenesis is complex and may be a step-wise process which is initiated by inactivation of the p53 pathway. Probes against transfusion translocations (fluorescence in situ hybridization, FISH, and silver in situ hybridization, SISH) may be used for tumor identification when histological analysis, immunohistochemistry and other pathological investigations are not fully or definitively diagnostic. Other sarcomas are characterized by complex karyotypes lacking specific activating translocations. 
Table I. Chromosomal translocations in sarcomas.

\begin{tabular}{|c|c|c|}
\hline Histological subtype & Translocation & Gene fusion \\
\hline Synovial sarcoma & $\mathrm{t}(\mathrm{X} ; 18)(\mathrm{p} 11.2 ; \mathrm{q} 11.2)$ & $\begin{array}{l}S Y T-S S X 1 \\
S Y T-S S X 2 \\
S Y T-S S X 4\end{array}$ \\
\hline Myxoid/round cell liposarcoma & $\begin{array}{l}\mathrm{t}(12 ; 16)(\mathrm{q} 13 ; \mathrm{p} 11) \\
\mathrm{t}(12 ; 22)(\mathrm{q} 13 ; \mathrm{q} 11)\end{array}$ & $\begin{array}{l}F U S-C H O P \\
E W S-C H O P\end{array}$ \\
\hline Alveolar rhabdomyosarcoma & $\begin{array}{l}\mathrm{t}(2: 13)(\mathrm{q} 35 ; \mathrm{q} 14) \\
\mathrm{t}(1: 13)(\mathrm{p} 36 ; \mathrm{q} 14)\end{array}$ & $\begin{array}{c}E W S-A T F 1 \\
P A X 3-F K H R\end{array}$ \\
\hline Alveolar soft part sarcoma & $\mathrm{t}(\mathrm{X} ; 17)(\mathrm{p} 11 ; \mathrm{q} 25)$ & $P A X 7-F K H R$ \\
\hline Desmoplastic round cell tumor & $\mathrm{t}(11 ; 22)(\mathrm{p} 13 ; \mathrm{q} 12)$ & $E W S-W T 1$ \\
\hline Epithelioid hemangioendothelioma & $\mathrm{t}(1 ; 3)(\mathrm{p} 36.3 ; \mathrm{q} 25)$ & Unknown \\
\hline Extraskeletal myxoid chondrosarcoma & $\begin{array}{l}\mathrm{t}(9 ; 22)(\mathrm{q} 22-\mathrm{q} 3 ; \mathrm{q} 12) \\
\mathrm{t}(9 ; 17)(\mathrm{q} 22: \mathrm{q} 11)\end{array}$ & $\begin{array}{c}E W S-N R 4 A 3 \\
T A F 15-N R 4 A 3\end{array}$ \\
\hline Ewing Sarcoma & $\mathrm{t}(11 ; 22)(\mathrm{q} 24 ; \mathrm{q} 12)$ & EWS-FLII \\
\hline
\end{tabular}

Adapted from ref (4).

\section{Imaging modalities}

Usually a CAT scan of the chest is performed when a mass lesion is first identified; this is often followed by a PET scan and CAT scan of the abdomen and pelvis and a bone scan as well as an MRI of the brain to complete imaging. In sarcomas, MRI scans are usually ordered, particularly with mesotheliomas, due to the ability to identify layers of fascia and discern levels of invasion within layers of muscle, fat and connective tissue on T1 and T2 images enhanced with gadolinium contrast. Sarcomas of the bone and cartilage, particularly those located in the extremities, are staged with MRI of the affected limb and CAT scans of the chest, abdomen and pelvis.

PET scans have been shown to be useful in the staging of certain sarcomas. Currently Medicare only allows for PET scans in patients with solitary pulmonary nodules and for the staging of more common tumors, including colon cancers, non-small cell lung cancers, melanomas and lymphomas.

\section{Surgical approaches and techniques}

Before making an attempt at surgical resection, different modes of resection must be considered, including thoracotomy followed by pneumonectomy, wedge resection or lobectomy. Less severe surgery is favored due to the occasional bilateral nature of metastatic disease and the occasional need for resections at different times. More extensive surgery, however, is favored as part of trimodality therapy (chemotherapy, surgery, radiation therapy) in individuals with mesothelioma. Thoracoscopy, bronchoscopy and mediastinoscopy have important roles. Due to the importance of directly visualizing both the parietal and visceral pleura for subtle evidence of metastatic involvement, less invasive modalities than thoracotomy may occasionally be used to determine resectability. Thoracotomy unfortunately remains the mainstay of metastectomy due to the wide exposure a traditional thoracotomy incision confers. As in non-small cell lung cancer, direct visual inspection of the chest cavity may lead to immediate surgical upstaging of a tumor and may occasionally necessitate that curative surgery either be aborted or deferred to another time. Surgical treatment of pulmonary metastases changes the natural history of the disease (5-18).

Video-assisted thoracic surgery (VATS; previously referred to as pleuroscopy) is a less invasive form of thoracic surgery which has become increasingly popular over the last 20 years. A trained thoracic surgeon uses a video camera attached to a modified endoscope to inspect the pleura and perform diagnostic and therapeutic procedures. The introduction of stapling through the thoracoscope has enabled thoracic surgeons to perform surgical procedures through the VATS procedure that would previously have been performed through an open thoracotomy. Specifically, lobectomy and wedge resections may be performed through VATS procedures without the prolonged healing time associated the more traditional thoracotomy. VATS lobectomies are similar to open lobectomies in that the pulmonary anatomy remains the same; branches of the pulmonary arteries and veins, as well as the bronchus to the involved lobe, must be divided and ligated prior to resection. Whether VATS may become a mainstay in metastectomy is questionable due to the scarring surrounding certain metastatic lesions following exposure to neoadjuvant treatment. Extensive reconstruction of vascular structures, which is commonly carried out in extremity sarcomas, is generally not performed with central vasculature when resecting pulmonary sarcomas (19-23).

When there is a question of mediastinal involvement, direct inspection of the anterior mediastinum, which allows inspection and sampling of level 2, 4 and 7 lymph nodes, should be performed. A traditional mediastinoscopy starts with an incision at the sternum, through which an extended mediastinoscopy may be carried out and lymph nodes in the preaortic position and aorto-pulmonary window (levels 6 and 5) may be 
sampled. The Chamberlain procedure, or paramedian mediastinotomy, which involves entering the mediastinum below the sternal notch from between the third and fourth ribs, is the standard procedure for obtaining lymph nodes from levels 5 and 6.

\section{Radiation therapy}

Radiation therapy is not often used in the treatment of sarcomas of the chest, except in a palliative role. Sarcomas are generally not sensitive to radiation; normal lung tissue may be killed at a dose of more than 2,000 cGy, whereas sarcomas require 6,000 to 10,000 cGy for eradication. Cyber-knife therapy may have a role for single metastatic lesions but cannot be used for large or multiple lesions. Similarly, adjuvant radiation, useful in extremity sarcomas, is not generally useful in lung sarcomas (24-28).

\section{Chemotherapy and targeted therapy}

Unlike lymphomas, which are also derived from the mesoderm, sarcomas are not generally curable with chemotherapy. Most studies of chemotherapy efficacy mix these tumors due to the rarity of individual multiple histologies, except perhaps for mesotheliomas. Starting in the 1970s, several different schools of thought predominated on the treatment of soft tissue sarcomas. Arterial infusions of Adriamycin were used for extremity sarcoma (29). Cisplatin-based multi-agent protocols were utilized at the Mayo clinic, while multi-agent regimens containing ifosfamide, mesna, dacarbazine and Adriamycin were developed at Memorial Sloan Kettering and Dana Farber (30). High-dose methotrexate, with Adriamycin and ifosfamide, was found to be an active combination in osteosarcomas (31). Before a great variety of drugs was available, much time was spent developing novel regimens that could be administered as prolonged infusions over $24 \mathrm{~h}$ to one week or over a short period of time to achieve a high peak plasma concentration. Numerous other agents, including dacarbazine, doxorubicin and ifosfamide, were developed using different treatment schedules (32-38). Gemcitabine and Taxotere were found to act synergistically in metastatic leiomyosarcomas (39). The differential sensitivity of certain sarcomas to other agents, including angiosarcomas to taxanes and mixed mullerian tumors, particularly high grade carcinosarcomas, to ifosfamide and cisplatin, further muddies the water regarding differential sensitivity to various agents. With the advent of Gleevec, the prototypal targeted therapy for select sarcomas, it is possible to use other targeted agents with targeted therapy (40). Even with some low-grade or borderline malignant tumors previously thought to be insensitive to chemotherapy, there are now data that indicate that chemotherapy has a role, as in desmoid tumors (41-43). This landscape is further complicated by data which have been confusing with regard to the long-term benefit of adjuvant chemotherapy in limited stage soft tissue sarcomas (44-47). The treatment choices may now be molecularly driven with our increasing knowledge of translocations and gene fusion products (48-51).

A number of the studies on extremity sarcomas have been directed toward reducing the size of extremity sarcomas, such that limb-sparing surgery may be performed. The same approach may be utilized in patients with lung metastases from primary sarcomas. Treatment should be tailored as much as possible to the subtype. As medical knowledge further characterizes these translocations and the oncogenes that may be amplified as a result, more targeted agents are likely to become available. Knowledge of these translocations is paramount in making appropriate diagnoses as numerous probes have become commercially available that are able to identify, by FISH, the presence of certain diagnostic mutations.

Exact diagnoses are paramount, as different types of sarcomas require different types of systemic treatment. Low-grade sarcomas have been thought to be insensitive to chemotherapy, though this is not always the case. Intermediateand high-grade sarcomas exhibit differential sensitivity to cytotoxic agents. The location of tumors may be predictive of responses, but histology is more accurate. Pediatric sarcomas present special cases; in particular, Ewing sarcoma, the Ewing sarcoma family of tumors and osteosarcomas require specialized treatment protocols developed for the pediatric population. Targeted therapy has value in gastrointestinal stromal tumors (GISTs). The relative rarity of individual subtypes belies their importance in illustrating the importance of tailoring therapy to specific histology, biology and location. The development of specialized target therapies has allowed progression beyond the inaccurate treatment paradigms which have become outdated in the past 10 years, and which mandated that all intermediate- and high-grade lesions be treated with combinations of doxorubicin, ifosfamide and dacarbazine or not at all, and that low-grade sarcomas need not be treated at all, except by the surgeon and radiotherapist, due to their supposed insensitivity to drug therapy. Despite the more aggressive nature of intermediate- and high-grade lesions, they respond at a higher rate to chemotherapy than do low-grade regimens.

The relative insensitivity of low-grade sarcomas to chemotherapy should not suggest that they are insensitive to all forms of therapy; rather it indicates the need for subtyping individual sarcomas and for immunohistochemical phenotyping and molecular genotyping.

It is known that differential drug sensitivities exist in sarcomas. Doxil and taxanes are recommended for angiosarcomas previously considered to be insensitive to chemotherapy (52). Sunitimab is recommended for alveolar soft tissue sarcoma (53). Combinations of Adriamycin, ifosfamide and methotrexate remain the mainstay of treatment for osteosarcomas. Rhabdomyosarcomas are best treated with vincristine, Adriamycin and Cytoxan in combination. Gemcitabine and Taxotere are particularly effective in GI leiomysarcomas and myxoid round cell tumors are particularly sensitive to trabectedin (54). Synovial sarcomas also appear to be sensitive to trabectedin as well as to traditional regimens which contain Adriamycin and ifosfamide and Nexavar, as do small round cell tumors (55-58). Chondrosarcomas remain amongst the tumors which are insensitive to chemotherapy, particularly the grade I sarcomas whereas the grades II and III sarcomas, particularly the mesenchymal subtype, do have some sensitivity to Adriamycin- and ifosfamide-based regimens (59). Epithelioid sarcomas are also known for tumor resistant behavior amongst soft tissue sarcomas (60).

Sirolimus appears to have activity in perivascular epithelial cell tumors (recurrent angiomyolipoma/lymphangioleiomyo- 
matosis) (61-64). With the advent of molecular genotyping and phenotyping, these and other sensitivites may be prospectively studied and predicted (65). Further development should focus on less toxic agents, including VEGF inhibitors, tyrosine kinase inhibitors, PDGFR inhibitors, EGFR inhibitors and agents with novel mechanisms of action $(66,67)$. mTOR inhibitors have been studied in the metastatic sarcoma subpopulation. Ridaforolimus, a rapamycin analog, has been studied in sarcomas and may confer stability of disease while not having the adverse toxicities of combination chemotherapy (68-71). The SUCCEED trial has studied this drug at multiple centers (72).

The histogenesis of soft tissue sarcomas may point to the efficacy of therapy that targets signal transduction. Soft tissue sarcomas are thought to be derived from primitive mesenchymal cells which are found throughout the body, not just in mesodermal derivatives such as supportive tissue and muscle. Common pathways may be dysregulated when activated in different sarcoma subtypes.

Most practicing oncologists are familiar with routine rejections for off-label uses of newer, more expensive chemotherapies and targeted therapies. Unfortunately, the relative rarity of sarcomas ensures that large randomized protocols are unlikely to occur for most newer targeted therapies. Rather, evidence may consist of pooled data, small studies, cooperative groups, phase II studies and case reports. Since level I data do not exist, oncologists may find themselves as unwitting activists for access to tailored therapies. As many sarcomas occur in the younger population, physicians may be called on to advocate for access to expensive drugs that, over the long-term, may provide disease stability (73-76). Considering individual sarcomas as 'orphan diseases' so that proper and efficacious medicines may be developed and offered for treatment may be a solution; advocacy for other relatively rare disease, including Gaucher's disease and hemophilia A and B, has resulted in numerous effective therapies along with long-term disease management with decreasing morbidity and mortality. The costs of such therapies are insignificant when compared with the human costs of no, toxic or ineffective therapies.

\section{References}

1. Aljubran AH, Griffin A, Pintilie $M$ and Blackstein $M$ Osteosarcoma in adolescents and adults: survival analysis with and without lung metastases. Ann Oncol 20: 1136-1141, 2009.

2. Potter DA, Glenn J, Kinsella T, et al: Patterns of recurrence in patients with high-grade soft tissue sarcomas. J Clin Oncol 3: 353-366, 1985.

3. Casson AG, Putnam JB, Natarajan G, et al: Efficacy of pulmonary metastasectomy for recurrent soft tissue sarcoma. J Surg Oncol 47: 1-4, 1991

4. Laydanyi M, Antonescu CR and Dal Cin P: Cytogenetic and Molecular Genetic Pathology of Soft Tissue Tumors. In: Enzinger and Weiss's Soft Tissue Tumors. Weiss SW and Goldblum Jr (eds). Mosby, St. Louis, MO, pp73-102, 2008.

5. Abdalla EK and Pisters PW: Metastasectomy for limited metastases from soft tissue sarcoma. Curr Treat Options Oncol 3: 497-505, 2002.

6. Casson AG, Putnam JB, Natarajan G, et al: Five-year survival after pulmonary metastasectomy for adult soft tissue sarcoma. Cancer 69: 662-668, 1992.

7. Chao C and Goldberg M: Surgical treatment of metastatic pulmonary soft-tissue sarcoma. Oncology (Williston Park) 14 835-841, 2000; discussion 842-844, 847.
8. Horan TA, Santiago FF and Araujo LM: The benefit of pulmonary metastectomy for bone and soft tissue sarcomas. Int Surg 85: 185-189, 2000.

9. Lanza LA, Putnam JB, Benjamin RS and Roth JA: Response to chemotherapy does not predict survival after resection of sarcomatous pulmonary metastases. Ann Thorac Surg 51: 219-224, 1991.

10. Predina JD, Puc MM, MD, Bergey MR, Sonnad SS, Kucharczuk JC, Staddon A, Kaiser LR and Shrager JB: Improved survival after pulmonary metastasectomy for soft tissue sarcoma. J Thorac Oncol 6: 913-919, 2011.

11. Putnam JB Jr and Roth JA: Surgical treatment for pulmonary metastases from sarcoma. Hematol Oncol Clin North Am 9: 869-887, 1995.

12. Quiros RM and Scott WJ: Surgical treatment of metastatic disease to the lung. Semin Oncol 35: 134-146, 2008.

13. Roth JA, Putnam JB Jr, Wesley MN and Rosenberg SA: Differing determinants of prognosis following resection of pulmonary metastases from osteogenic and soft tissue sarcoma patient. Cancer 55: 1361-1366, 1985.

14. Snyder CL, Saltzman DA, Ferrell KL, Thompson RC and Leonard AS: A new approach to the resection of pulmonary osteosarcoma metastases. Results of aggressive metastasectomy. Clin Orthop Relat Res 270: 247-253, 1991.

15. Sternberg DI and Sonett JR: Surgical therapy of lung metastases. Semin Oncol 34: 186-196, 2007.

16. Stephens EH, Blackmon SH, Correa AM, et al: Progression after chemotherapy is a novel predictor of poor outcomes after pulmonary metastasectomy in sarcoma patients. J Am Coll Surg 212: 821-826, 2011.

17. Sugarbaker DJ, Garcia JP, Richards WG, et al: Extrapleural pneumonectomy in the multimodality therapy of malignant pleural mesothelioma. Results in 120 consecutive patients. Ann Surg 224: 288-294, 1996; discussion 294-296.

18. van Geel AN, Pastorino U, Jauch KW, et al: Surgical treatment of lung metastases: The European Organization for Research and Treatment of Cancer-Soft Tissue and Bone Sarcoma Group study of 255 patients. Cancer 77: 675-682, 1996.

19. Daylami R, Amiri A, Goldsmith B, Troppmann C, Schneider PD and Khatri VP: Inferior vena cava leiomyosarcoma: is reconstruction necessary after resection? J Am Coll Surg 210: 185-190, 2010.

20. Lohman RF, Nabawi AS, Reece GP, et al: Soft tissue sarcoma of the upper extremity: a 5-year experience at two institutions emphasizing the role of soft tissue flap reconstruction. Cancer 94: 2256-2264, 2002.

21. Marcove RC, Sheth DS, Healey J, et al: Limb-sparing surgery for extremity sarcoma. Cancer Invest 12: 497-504, 1994.

22. Valle AA and Kraybill WG: Management of soft tissue sarcomas of the extremity in adults. J Surg Oncol 63: 271-279, 1996.

23. Williard WC, Collin C, Casper ES, et al: The changing role of amputation for soft tissue sarcoma of the extremity in adults. Surg Gynecol Obstet 175: 389-396, 1992.

24. Pollack A, Zagars GK, Goswitz MS, et al: Preoperative vs. postoperative radiotherapy in the treatment of soft tissue sarcomas: a matter of presentation. Int J Radiat Oncol Biol Phys 42: 563-572, 1998.

25. Schmidt RA, Conrad EU III, Collins C, and Rabinovich A and Finney A: Measurement and prediction of the short-term response of soft tissue sarcomas to chemotherapy. Cancer 72: 2593-2601, 1993.

26. Schoenfeld GS, Morris CG, Scarborough MT and Zlotecki RA: Adjuvant radiotherapy in the management of soft tissue sarcoma involving the distal extremities. Am J Clin Oncol 29: 62-65, 2006.

27. Temple WJ, Temple CL, Arthur K, et al: Prospective cohort study of neoadjuvant treatment in conservative surgery of soft tissue sarcomas. Ann Surg Oncol 4: 586-590, 1997.

28. Yang JC, Chang AE, Baker AR, et al: Randomized prospective study of the benefit of adjuvant radiation therapy in the treatment of soft tissue sarcomas of the extremity. J Clin Oncol 16: 197-203, 1998.

29. Eilber F, Guiliano AE, Huth JF, et al: Intravenous versus intraarterial Adriamycin, 2800 radiation and surgical excision for extremity soft tissue sarcomas. A randomized prospective trial. ASCO Proceedings 9: 309, 1990.

30. Taub RN and Antman KH: Soft tissue tumors. In: Current Therapy in Cancer. Foley JF, Vose JM and Armitage JO (eds). WB Saunders Company, Philadelphia, PA, pp259-270, 1999. 
31. Rosen G, Forscher CA, Eilberg FR, et al: Osteogenic sarcoma. In: Cancer Treatment. Haskell CM (ed). WB Saunders Company, Philadelphia, PA, pp1244-1258, 2001.

32. Antman K, Crowley J, Balcerzak SP, et al: An intergroup phase III randomized study of doxorubicin and dacarbazine with or without ifosfamide and mesna in advanced soft tissue and bone sarcomas. J Clin Oncol 11: 1276-1285, 1993.

33. Borden EC, Amato DA, Rosenbaum C, et al: Randomized comparison of three adriamycin regimens for metastatic soft tissue sarcomas. J Clin Oncol 5: 840-850, 1987.

34. Del Muro XG, Pousa AL, Buesa JM, et al: Temozolamide as a 6-week continuous oral schedule in advance soft tissue sarcoma (STS): a phase II trial of the Spanish Group for Research on Sarcomas (GEIS). ASCO proceedings. (abstract 1412), 2001.

35. Gottlieb JA, Benjamin RS, Baker LH, et al: Role of DTIC (NSC-45388) in the chemotherapy of sarcomas. Cancer Treat Rep 60: 199-203, 1976.

36. Rosen G, Chawla S, Hamburg S, Loweqbraun: Phase II study of high dose continuous infusion dimethyl triazeno carboxamide (DTIC) in metastatic leiomyosarcoma. ASCO proceedings (abstract 1210), 1990

37. Santoro A, Tursz T, Mouridsen H, et al: Doxorubicin versus CYVADIC versus doxorubicin plus ifosfamide in first-line treatment of advanced soft tissue sarcomas: a randomized study of the European Organization for Research and Treatment of Cancer Soft Tissue and Bone Sarcoma Group. J Clin Oncol 13: $1537-1545,1995$

38. Zalupski M, Metch B, Balcerzak S, et al: Phase III comparison of doxorubicin and dacarbazine given by bolus versus infusion in patients with soft-tissue sarcomas: a Southwest Oncology Group study. J Natl Cancer Inst 83: 926-932, 1991.

39. Hensley ML, Maki R, Venkatraman E, et al: Gemcitabine and docetaxel in patients with unresectable leiomyosarcoma: results of a phase II trial. J Clin Oncol 20: 2824-2831, 2002.

40. Blanke CD, Demetri GD, von Mehren M, et al: Long-term results from a randomized phase II trial of standard- versus higher-dose imatinib mesylate for patients with unresectable or metastatic gastrointestinal stromal tumors expressing KIT. J Clin Oncol 26 : 620-625, 2008

41. Garbay D, Le Cesne A, Penel N, Chevreau C, Marec-Berard P Blay JY, Debled M, Isambert N, Thyss A, Bompas E, et al: Chemotherapy in patients with desmoid tumors: a study from the French Sarcoma Group (FSG). Ann Oncol 23: 182-186, 2012.

42. Gounder MM, Lefkowitz RA, Keohan ML, D'Adamo DR Hameed M, Antonescu CR, Singer S, Stout K, Ahn L and Maki RG: Activity of Sorafenib against desmoid tumor/deep fibromatosis. Clin Cancer Res 15: 17: 4082-4090, 2011.

43. Knechtel G, Stoeger H, Szkandera J, Dorr K, Beham A and Samonigg H: Desmoid tumor treated with polychemotherapy followed by imatinib: a case report and review of the literature. Case Rep Oncol 3: 287-293, 2010.

44. No authors listed: Adjuvant chemotherapy for localised resectable soft-tissue sarcoma of adults: meta-analysis of individual data. Sarcoma Meta-analysis Collaboration. Lancet 350: 1647-1654, 1997.

45. Frustaci S, Gherlinzoni F, De Paoli A, et al: Adjuvant chemotherapy for adult soft tissue sarcomas of the extremities and girdles: results of the Italian randomized cooperative trial. J Clin Oncol 19: 1238-1247, 2001

46. Lewis JJ, Leung D, Woodruff JM, et al: Retroperitoneal softtissue sarcoma: analysis of 500 patients treated and followed at a single institution. Ann Surg 228: 355-365, 1998.

47. O'Byrne K and Steward WP: The role of adjuvant chemotherapy in the treatment of adult soft tissue sarcomas. Crit Rev Oncol Hematol 27: 221-227, 1998

48. Allen KE and Weiss GJ: Resistance may not be futile: microRNA biomarkers for chemoresistance and potential therapeutics. Mol Cancer Ther 9: 3126-3136, 2010.

49. Nielsen TO and West RB: Translating gene expression into clinical care: sarcomas as a paradigm. J Clin Oncol 28: 1796-1805, 2010

50. Weiss GJ, Alarcon A, Halepota M, Penny RJ and Von Hoff DD: Molecular characterization of interdigitating dendritic cell sarcoma. Rare Tumors 2: e50, 2010.

51. Riedel RF: Targeted agents for sarcoma: is individualized therapy possible in such a diverse tumor type? Semin Oncol 38 (Suppl 3): S30-S42, 2011.

52. Fury MG, Antonescu CR, Van Zee KJ, et al: A 14-year retrospective review of angiosarcoma: clinical characteristics, prognostic factors and treatment outcomes with surgery and chemotherapy. Cancer J 11: 241-247, 2005.
53. Palassini E, Stachiotti S, Negri T, et al: Sunitinib malate (SM) in alveolar soft part sarcoma (ASPS). J Clin Oncol 28 (Suppl): $15 \mathrm{~s}, 2010$.

54. Boudou L, Baconnier M, Blay JY, Lombard-Bohas C and Cassier PA: Trabectedin for the management of soft-tissue sarcoma. Anticancer Ther 9: 727-737, 2009.

55. Basso U, Brunello A, Bertuzzi A and Santoro A: Sorafenib is active on lung metastases from synovial sarcoma. Ann Oncol 20: 386-387, 2009

56. Maki RG, D'Adamo DR, Keohan ML, et al: Phase II study of sorafenib in patients with metastatic or recurrent sarcomas. J Clin Oncol 27: 3133-3140, 2009.

57. Peng CL, Guo W, Ji T, Ren T, Yang Y, Li DS, Qu HY, Li X, Tang S, Yan TQ and Tang XD: Sorafenib induces growth inhibition and apoptosis in human synovial sarcoma cells via inhibiting the RAF/MEK/ERK signaling pathway. Cancer Biol Ther 8: 1729-1736, 2009.

58. Shitara T, Shimada A, Hanada R, Matsunaga T, Kawa K, Mugishima H, Sugimoto T, Mimaya J, Manabe A, Tsurusawa M and Tsuchida Y: Irinotecan for children with relapsed solid tumors. Pediatr Hematol Oncol 23: 103-110, 2006.

59. Herget GW, Uhl M, Opitz OG, et al: The many faces of chondrosarcoma of bone, own cases and review of the literature with an emphasis on radiology, pathology and treatment. Acta Chir Orthop Traumatol Cech 78: 501-509, 2011.

60. Dei Tos AP, Wagner AJ, Modena P, Comandone A and Leyvraz S: Epithelioid soft tissue tumors. Semin Oncol 36: 347-357, 2009.

61. Bissler JJ, McCormack FX, Young LR, et al: Sirolimus for angiomyolipoma in tuberous sclerosis complex or lymphangioleiomyomatosis. N Engl J Med 358: 140-151, 2008

62. Davies DM, Johnson SR, Tattersfield AE, et al: Sirolimus therapy in tuberous sclerosis or sporadic lymphangioleiomyomatosis. N Engl J Med 358: 200-203, 2008

63. Taillé C, Debray MP and Crestani B: Sirolimus treatment for pulmonary lymphangioleiomyomatosis. Ann Intern Med 146: 687-688, 2007.

64. Wagner AJ, Malinowska-Kolodziej I, Morgan JA, et al: Clinical activity of mTOR inhibition with sirolimus in malignant perivascular epithelioid cell tumors: targeting the pathogenic activation of mTORC1 in tumors. J Clin Oncol 28: 835, 2010.

65. Looyenga BD, Cherni I, Mackeigan JP and Weiss GJ: Tailoring tyrosine kinase inhibitors to fit the lung cancer genome. Transl Oncol 4: 59-70, 2011.

66. D'Adamo DR: Integrating novel therapies into the treatment of sarcoma: A multidisciplinary approach - introduction. Semin Oncol 38 (Suppl 3): S1-S2, 2011.

67. Demicco EG and Lazar AJ: Clinicopathologic considerations: how can we fine tune our approach to sarcoma? Semin Oncol 38 (Suppl 3): S3-S18, 2011.

68. Chawla SP, Tolcher AW, Staddon AP, et al: Survival results with AP23573, a novel mTOR inhibitor, in patients (pts) with advanced soft tissue or bone sarcomas: Update of phase II trial. J Clin Oncol 25 (Suppl): 18S, 2007.

69. Hartford CM, Desai AA, Janisch L, et al: A phase I trial to determine the safety, tolerability, and maximum tolerated dose of deforolimus in patients with advanced malignancies. Clin Cancer Res 15: 1428-1434, 2009.

70. Mita MM, Britten CD, Poplin E, et al: Deforolimus trial 106 - a phase I trial evaluating 7 regimens of oral deforolimus (AP23573, MK-8669). J Clin Oncol 26: 3509, 2008

71. Mita MM, Mita AC, Chu QS, et al: Phase I trial of the novel mammalian target of rapamycin inhibitor deforolimus (AP23573; MK-8669) administered intravenously daily for 5 days every 2 weeks to patients with advanced malignancies. J Clin Oncol 26: 361-367, 2008

72. Chalwa SP, Blay J, Ray-Coquard, et al: Results of the phase III, placebo-controlled trial (SUCCEED) evaluating the mTOR inhibitor ridaforolimus (R) as maintenance therapy in advanced sarcoma patients (pts) following clinical benefit from prior standard cytotoxic chemotherapy (CT). J Clin Oncol 29: abstract 10005, 2011.

73. Collin CF, Friedrich C, Godbold J, et al: Prognostic factors for local recurrence and survival in patients with localized extremity soft-tissue sarcoma. Semin Surg Oncol 4: 30-37, 1988.

74. Fanucchi M: Update of the management of connective tissue malignancies. Semin Oncol 31 (Suppl 4): 16-19, 2004.

75. Soliman H, Ferrari A and Thomas D: Sarcoma in the young adult population: an international view. Semin Oncol 36: 227-236, 2009.

76. Patel SR, Zagars GK and Pisters PWT: The follow-up of adult soft-tissue sarcomas. Semin Oncol 30: 413-416, 2003. 